\title{
Reflexões sobre o planejamento territorial e a dimensão rural
}

Thoughts on land planning and the rural dimension

Paulo Renato Mesquita Pellegrino*, Martina Croso Mazzuco**

*Universidade de São Paulo, Brasil, prmpelle@usp.br

**Universidade de São Paulo, Brasil, martina.mazzuco@usp.br
Palavras-chave:

Planejamento;

Conservação ambiental;

Bioregiões.

\section{Keywords:}

Land planning;

Bioregions.
Ecological conservation;

\section{Resumo}

$O$ planejamento de territórios se tornou uma ciência no século $X X$, formalizada a partir de uma necessidade de melhor ordenar o espaço, os fluxos e recursos disponíveis em um mundo em rápida transformação. O planejamento dos territórios não urbanizados é um tópico ainda pouco explorado. Atualmente, o valor das áreas não urbanizadas se torna dia a dia mais evidente. Áreas rurais e áreas selvagens representam aproximadamente $97 \%$ da superfície terrestre, e concentram os maiores fragmentos de ecossistemas naturais no planeta, fundamentais para o equilíbrio da biosfera. O planejamento territorial com foco na rural requer uma metodologia que expresse a dinâmica e a natureza socioambiental local e seja orientada por um propósito central: a restauração dos ecossistemas naturais do planeta. Neste artigo, apresentamos as origens da ciência do planejamento territorial, mencionamos modelos alternativos de governança e gestão, e refletimos sobre como planejar territórios a partir de uma maior condição de permeabilidade, contribuindo para a estruturação de territórios mais inclusivos, transparentes e colaborativos para o longo prazo. prazo.

\section{arq.urb}

número 32 | set - dez de 2021 Recebido: 18/08/2021 Aceito: 03/11/202

\section{Abstract}

Planning became a science in the 20th century. Land planning was developed as a response to the need to better organize spatial dynamics and the flow of resources in a rapidly changing world. Non-urban land planning is a field still little developed. Currently, the value of non-urban and areas, which represent a total of $97 \%$ of the land surface, is becoming more evident day by day. Non-urban land, composed of rural areas and wilderness, concentrates the largest fragments of natural ecosystems on the planet, essential for the balance of the biosphere. Land planning focused on the rural dimension requires a methodology that specifically responds to local dynamics and socioecological conditions, and is oriented towards the conservation of the local ecological and social dimension. In this article we present the origins of the science of territorial planning, mention alternative governance and management models and reflect on how land planning can contribute to a more transparent, inclusive and collaborative reality for the long run.

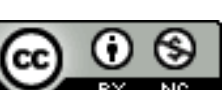




\section{Introdução}

Territórios dotados de características únicas são produzidos por infinitas combinações de elementos e processos. Durante bilhões de anos, o planeta Terra foi moldado unicamente por processos naturais, promovidos pela ação das plantas, animais, clima, movimentos geológicos. Em um período mais recente de sua história, a Terra passou a contar com a força transformadora da ação humana na configuração de seus territórios. Os territórios que criamos, por sua vez, determinarão a qualidade das relações que se estabelecerão sobre ele.

O planejamento de territórios é uma ciência relativamente nova, ainda que seja praticada socialmente há milhares de anos. Se baseia nos valores e habilidades da comunidade que o conduz, nas técnicas disponíveis em cada espaço e tempo, nas características locais. O planejamento se manifesta através de desenhos, diretrizes, planos de ação, metas, métricas, ferramentas de gestão. De relevante complexidade, o alcance do processo de planejamento de territórios ainda não é plenamente compreendido (MASSIRIS, 2005). Visualizar, reconhecer, mapear, interpretar, assimilar, conectar e agir: planejar é uma habilidade cognitiva que se desenvolve a partir de uma realidade presente, que será então conectada à uma realidade vislumbrada - O planejamento é uma ciência essencialmente transformadora. A ideação é, assim, uma das primeiras etapas do planejamento. Talvez a primeira seja o reconhecimento da necessidade de mudança.

A mudança é uma qualidade marcante dos tempos atuais. A alta conectividade do planeta permite que informações, pessoas, ideias, mercadorias, ecossistemas, climas, se transformem em alta velocidade. A ciência do planejamento territorial deve acompanhar estes movimentos e, antenada aos desafios atuais e previsões futuras, oferecer alternativas palpáveis e, especialmente, um caminho claro para a ação. Uma ação ao alcance de cada indivíduo e comunicável à diferentes grupos sociais.

Este estudo apresenta uma reflexão sobre o planejamento territorial, descrevendo a origem dessa ciência, seu propósito e a forma como atua em diferentes contextos e escalas. A partir do fenômeno do território, o planejamento tem como objetivo prognosticar situações e propor alternativas e ações que sirvam aos mais variados propósitos. Discutiremos os valores que embasam o planejamento territorial, e sua relevância como disciplina e prática profissional nos dias atuais, em um planeta cada vez mais suscetível à pressão imposta pela sociedade humana. $O$ estudo oferece um enfoque específico ao planejamento territorial rural, discutindo a sua importância e a multiplicidade de desafios a serem observados em sua prática.

Dentre as diferentes possíveis unidades espaciais de planejamento territorial, descrevemos o conceito de Bioregião como uma unidade espacial chave para o mais relevante objetivo da atualidade - a restauração dos tecidos ecológicos e sociais do nosso planeta (ABRAMOVAY, 2021). O conceito de Bioregião expressa a junção de conceitos como o desenvolvimento sustentável, a localização, a construção de respostas adequadas ao contexto local. Uma das sementes do conceito de Bioregião é o incentivo ao desenvolvimento de polos de inovação regionais, fundamentados nos recursos materiais e imateriais locais, e que podem contribuir para a descentralização dos sistemas econômicos. A descentralização pressupõe a criação de novas estruturas de governança, ramificadas e melhor distribuídas no território.

Este estudo tem como objetivo apresentar uma estrutura conceitual para uma abordagem metodológica integrada de planejamento, sugerindo possíveis alternativas para uma realidade mais participativa e alinhada com a natureza dos territórios onde vivemos.

\section{O Planejamento Territorial}

Planejamos algo com o intuito de orientar cenários na direção de objetivos específicos, antevendo circunstâncias e ajustando as variáveis que estão visíveis e compreensíveis a nós, e sobre as quais temos alguma forma de controle. A atividade de planejamento territorial sempre foi parte intrínseca ao desenvolvimento humano, fundamental historicamente para a transformação na forma como interagimos com o meio físico, como manejamos recursos naturais e ordenamos espacialmente a infraestrutura e as dinâmicas sociais.

No início do século XX o planejamento foi formalizado como ciência e campo de atuação profissional, aplicado a áreas de conhecimento variadas, incluindo o planejamento ambiental, econômico e social (FRIEDMANN, 1987). No entanto, as bases teóricas que fundamentaram o planejamento moderno surgiram dois séculos antes. Entender o contexto no qual a ciência do planejamento nasceu e os valores básicos que a embasam, é fundamental para refletirmos sobre sua relevância e os propósitos a que serve. 
No século XVIII, a humanidade desenvolve uma nova corrente de pensamento que enfatiza a razão acima de outras virtudes e o valor da ciência para a resolução dos problemas sociais (MAXWELL, 2017). A Era do lluminismo rompe com vertentes de pensamento e governança fundamentadas no misticismo e na religião, propondo uma nova ordem de valores baseada na compreensão do Universo a partir do conhecimento das leis naturais e da lógica. Acreditava-se que este era o caminho para a construção de cenários previsíveis e estáveis para a sociedade. A influência do lluminismo foi determinante ao desenvolvimento humano nas décadas seguintes, informando estratégias de tomadas de decisão e ações baseadas no conhecimento e na técnica. Segundo Santos, a técnica engloba um conjunto de tecnologias e o nível de conhecimento para manejá-las (SANTOS, 2002). A confiança na técnica incentiva, assim, a ascensão do profissional qualificado como agente central do planejamento.

O aperfeiçoamento da técnica representa o crescente domínio do ser humano sobre o meio físico, a transformação dos processos organizacionais e a velocidade dos fluxos de informação. O desenvolvimento industrial, os novos processos produtivos, a reorganização territorial, o crescimento populacional e o desenvolvimento científico foram movimentos intensificados na transição do século XIX ao XX. As cidades emergem, então, como importantes centralidades. No Brasil, em 1940, a população urbana correspondia a 26,3\% (18,8 milhões) da população brasileira. Em 2000, sessenta anos depois, o percentual da população urbana era de $81,2 \%$ (138 milhões de pessoas) (MARICATO, 2000). O planejamento territorial moderno foi desenvolvido neste período a partir da perspectiva da experiência urbana.

Com o fortalecimento do fenômeno das cidades, a resolução dos conflitos e desafios urbanos ocupam o centro das discussões e das políticas públicas. Assim, criaram-se mecanismos específicos de planejamento territorial como o zoneamento, os gabaritos de altura, as taxas e coeficientes de ocupação, a função social da propriedade. No âmbito legal surgiram instrumentos como o Estatuto da Cidade, o Plano Diretor, o Código de Obras e a Lei de Uso e Ocupação do Solo, para tratar de questões como o adensamento populacional, a mobilidade, o saneamento, e a máxima eficiência do uso do solo. Muitos destes instrumentos, criados a partir do planejamento territorial urbano, foram nas décadas seguintes transportados e adaptados para o planejamento territorial em outras escalas e localidades. $\mathrm{O}$ planejamento territorial surge com o intuito de racionalizar o desenvolvimento nacional, potencializando o grau de eficiência dos processos territoriais em resposta a uma lógica de mercado e capital cada vez mais fortes.

No final do século XX vemos surgir uma intensa produção literária sobre os danos consequentes à ação do ser humano no planeta. Neste período, estudos mais aprofundados sobre a natureza e as dinâmicas dos ecossistemas naturais se desenvolvem e passam a ser debatidos em círculos cada vez maiores, incentivando a reflexão sobre os meios de produção e consumo, estratégias de cultivo, manejo agrícola e saúde. Ecologia, agroecologia, medicina integrativa, antroposofia entre tantas outras áreas de estudo baseados em uma perspectiva mais sistêmica são desenvolvidos no Ocidente. O ordenamento político, social e ambiental, impulsionados pelo setor público, passam a ser gradualmente integrados à lógica do planejamento territorial, em resposta à crescente pressão de movimentos sociais, em constatação aos primeiros efeitos do sistema industrial capitalista (FRIEDMANN, 1987).

\section{O Propósito do Planejamento}

O planejamento territorial tem como objetivo contribuir para o desenvolvimento local, através da configuração espacial estratégica de seus componentes. Diferentes definições de planejamento territorial existem no mundo, porém todas entendem o planejamento como "a ideia de regular ou organizar o uso, ocupação e transformação do território em prol de seu aproveitamento ótimo" (MASSIRIS, 2015).

O termo "planejamento" tem origem na palavra italiana "pianta", que significa "planta de arquitetura", um desenho projetual bidimensional. O desenho é uma convenção que representa o ideal, uma visão de destino que motivará os participantes e trará claridade, coesão e propósito ao processo (LYNCH, 1984). Na prática, o planejamento é muito mais que um desenho. Enquanto este processo pode assumir diferentes formas, de forma geral, todas as metodologias de planejamento compartiIham as mesmas etapas básicas de desenvolvimento: 1. a definição do problema a ser resolvido; 2. o diagnóstico do contexto local; 3 . a proposição de melhorias a partir de uma estrutura de decisões; 4 . a seleção ou criação de mecanismos de ação e monitoramento.

A primeira etapa é a definição do problema a ser resolvido, seu propósito, a quem e ao que se destina o planejamento. Tais definições oferecerão o tom e a direção 
do processo (LYNCH, 1984). Em seguida, temos a etapa de diagnóstico, onde são coletadas informações sobre a situação com a qual lidamos. Com base no diagnóstico, na terceira etapa definimos as estratégias, decisões e medidas a serem tomadas na direção do cenário proposto. Para muitos, o planejamento é interrompido neste estágio. No entanto, o que seria do planejamento sem a definição de mecanismos de implantação e a condução da decisão à ação? Ação, monitoramento e ajuste são as últimas etapas do processo.

Para algumas correntes de pensamento, o planejamento se resume ao ordenamento físico-espacial, enquanto outras correntes entendem o planejamento como uma atividade mais multidimensional, "um processo integral e complexo cuja finalidade é a melhoria do bem estar social, a partir da consideração dos parâmetros de índole físico-territorial, sociais, culturais, econômicos e político-administrativos" (MENDÉZ, 1990 apud MASSARIS, 2015). Nesse sentido, o planejamento territorial não tem um fim - é um constante processo de aprendizado e transformação ( $\mathrm{LYNCH}, 1984)$. O planejamento territorial é uma ferramenta dedicada a mudanças, se tornando útil quando "se ocupa, principalmente, com fornecer informações a processos de transformação de sistemas” (FRIEDMANN, 1987).

O planejamento será mais preciso e confiável quanto maior a quantidade dos dados disponíveis sobre a realidade que se propõem planejar. $O$ processo se desenvolve a partir de diagnósticos reunidos em quatro classes de conhecimento - descritivo (o que é), analítico (por que é), prescritivo (o que pode ser) e normativo (o que deve ser) (CAMPBELL, 2012). As duas primeiras classes estão ligadas à atividade de diagnóstico, e as duas últimas à etapa de proposição. A multiplicidade de dados coletados é, no entanto, menos relevante do que a qualidade dos dados. Toda a coleta de dados pressupõe um trabalho prévio de seleção de dados relevantes ao problema em questão, e deve ser orientada por critérios e valores preestabelecidos e alinhados com o propósito. (LYNCH, 1984). A compreensão dos dados gera conhecimento, e o conhecimento é fundamental ao processo de planejamento, sem o qual as decisões tomadas (o como) se resumem a simples comandos isolados, e o propósito central (o porquê) que justifica as decisões permanece desconhecido à maioria dos integrantes do processo, sendo eventualmente esquecido.

Por conhecimento, entendemos fatos, evidências, interpretações, dados de natureza científica, experimental, intuitiva, estética, emocional. O que consideramos conhecimento será relevante para a composição do planejamento, influenciando a forma como as decisões são tomadas. Atualmente o processo de planejamento reconhece diferentes fontes de conhecimento, abrindo espaço para visões de mundo mais ricas e diversificadas, tornando o processo de planejamento mais inclusivo e participativo. (CAMPBELL, 2012).

\section{Planejando Mudanças}

Diante do atual cenário de crise global e colapso dos ecossistemas naturais e sociais, diferentes setores da sociedade buscam por alternativas. O recém lançado $\mathrm{Re}-$ latório do IPCC sobre as Mudanças Climáticas (2021) afirma que a crise ambiental atual é produto da ação humana no planeta.

"É inequívoco que a influência humana aqueceu a atmosfera, o oceano e a terra. Ocorreram mudanças rápidas e generalizadas na atmosfera, no oceano, na criosfera e biosfera". (IPCC, SPM, 2021, p.5)

"Em 2019, as concentrações de CO2 atmosférico foram mais altas que em qualquer período anterior dos últimos 2 milhões de anos. (...) Desde 1750, o aumento de concentrações de CO2 (47\%) e CH4 (156\%) superam amplamente, e as concentrações de $\mathrm{N} 2 \mathrm{O}$ são similares (23\%), às transformações naturais ocorridas entre os períodos glaciais e interglaciais dos últimos 800.000 anos" (IPCC, SPM, 2021, p.5).

O relatório foca em dois temas centrais: a crise climática e a degradação do solo. $O$ termo "degradação do solo" é mencionado mais de 300 vezes no documento (na versão do documento dedicada a formuladores de políticas) e é indicado como uma das principais causas da atual crise climática. A degradação do solo pode ser entendida como a interferência na capacidade do solo de sustentar processos naturais tal como o ciclo hidrológico, o ciclo do carbono e o ciclo de nutrientes, devido a alterações em suas condições estruturais e químicas. A principal causa da degradação do solo no mundo são os processos erosivos. A erosão é um processo gerado por atividades específicas de uso do solo, como o pastoreio intensivo, aragem do solo e adoção de práticas agrícolas insustentáveis (BORELLI, 2012).

Ainda no relatório, diferentes estratégias são recomendadas como alternativas para a crise ambiental, como a adoção de práticas agrícolas ecológicas, o uso de biochar para o sequestro de carbono e o reflorestamento. Estas e outras estratégias compõem uma abordagem de manejo do território denominada "Sustainable Land 
Management" ou SLM, que engloba o uso de técnicas específicas para a melhoria das condições ambientais, sociais e econômicas a partir de estratégias integradas de manejo do território (IPCC, 2021).

A ciência aponta que o planejamento territorial integrado, voltado à conservação ambiental, é atualmente a melhor estratégia reconhecida para a restauração do planeta, dando ênfase a mecanismos que contribuam para o reestabelecimento dos processos naturais. À medida em que compreendemos a relação de interdependência entre a sociedade humana e ecossistemas naturais, o território rural ganha uma nova importância e seu planejamento se torna atividade central na restauração do planeta e na construção de uma nova narrativa para a sociedade global.

\section{O Território Rural}

As áreas não urbanizadas ocupam cerca de $97 \%$ do território terrestre do planeta, e concentram as maiores porções de ecossistemas naturais existentes (WORLD BANK, 2013). Estes territórios se distribuem entre áreas rurais e regiões selvagens. Em uma descrição generalista, as áreas rurais podem ser classificadas como os espaços "onde as construções humanas e a infraestrutura ocupam áreas esparsas do território, dominado principalmente por campos e pastagens, florestas, água, montanha e desertos" (WIGGINS, 2001). A abundância de recursos naturais, no sentido quantitativo e não qualitativo, é uma condição real do território rural.

As definições de rural e ruralidade são variadas e extensas. Os primeiros estudos sobre o rural se baseavam em dados sobre a densidade demográfica, uso do solo, atividades produtivas e estruturas de governança. Eventualmente, a qualidade da cultura local passou a ser reconhecida para a caracterização do território, uma vez que a cultura determina valores e visões de mundo, bem como uma variação no uso de técnicas empregadas regionalmente. No Brasil, o IBGE utiliza três critérios básicos para a definição do que é rural e o que é urbano, que são: 1. O tamanho da população; 2. A dispersão da população, ou seja, sua densidade demográfica; 3. A distância dos principais centros urbanos (IBGE, 2017).

No final do século XIX, os estudos sobre o rural passaram a reconhecer a pressão gerada pelo meio urbano sobre o território rural como fator determinante para o desenvolvimento local. A atividade agrícola é a maior responsável pela configuração do território rural, ocupando atualmente $38 \%$ da área terrestre do planeta, sendo $1 / 3$ deste percentual usado como área de cultivo e 2/3 para o pastoreio de animais. A agricultura é apontada como a principal atividade responsável pela conversão de ecossistemas naturais (FAO, 2020).

Quando olhamos para a área rural, constatamos a multiplicidade de temas que compõem o território. Ecossistemas naturais, áreas agrícolas dedicadas a diferentes tipos de produção, residências, indústrias, serviços, são algumas das variadas funções contidas no território rural. O rural é essencialmente multifuncional. Diferentemente do urbano, facilmente percebido a partir da densidade de suas construções e qualidade de sua infraestrutura, o rural abrange ampla variação de paisagens, dos espaços rururbanos nas margens da cidade aos territórios onde predominam quase por completo os ecossistemas naturais (GALLENT, 2019). A forte presença de ecossistemas naturais, marcados pela variabilidade e capacidade de auto regulação, conferem ao rural seu elevado potencial de transformação - a paisagem muda de acordo com as condições climáticas, em primeiro lugar, e tais mudanças determinam o uso e cobertura do solo e o comportamento humano ao longo do ano. Os animais se movimentam, diferentes espécies vegetais entram em dormência, os cultivares agrícolas se alternam, as folhas caem, a chuva cessa, e assim toda a dinâmica rural muda de uma estação para outra. O rural é um espaço de troca e transição. Considerar, no processo de planejamento, a condição de impermanência do território oferece uma enorme vantagem, especialmente quando as causas da impermanência não são processos naturais regulares e previsíveis, mas sintomas de um sistema ambiental e social degradado. O reconhecimento de possíveis fatores e eventos extremos permite que sejam previstos, no planejamento, estratégias de adaptação para a conservação do território.

A conservação de ecossistemas naturais está atualmente sujeita a mecanismos legais que estabelecem Áreas de Preservação, tais como parques nacionais, reservas legais e unidades de conservação menores, distribuídas em porções fragmentadas e geralmente desconectadas em um território. No entanto, tais mecanismos são insuficientes para a resolução do cenário de degradação ambiental do planeta (BRUNCKHORST, 2001). A definição de melhores escalas de planejamento para o manejo otimizado dos recursos naturais pode representar importantes avanços na direção de garantir melhores condições ecológicas na área rural (OSTRUM, E. 1990). Atualmente o planejamento territorial rural tem maior enfoque na escala 
regional, onde predominam diretrizes de desenvolvimento gerais. Na escala da propriedade privada o planejamento se limita às determinações de uso e aproveitamento do solo, com um maior enfoque em práticas agrícolas e taxas de produtividade. No entanto, entre a escala regional e a escala privada encontra-se uma unidade espacial intermediária, que concentra o potencial para ações de planejamento mais coerentes e efetivas à construção de coesão entre os setores sociais, econômicos e ambientais - esta unidade é a Bioregião.

\section{As Bioregiões}

Se no século XIX e XX a prioridade da agenda global foi o desenvolvimento industrial e a racionalização de processos, o século XXI tem como prioridade a restauração da natureza. Nesse contexto, as diretrizes de planejamento territorial deverão ser reavaliadas, permitindo que a conservação ambiental não seja exclusiva de alguns espaços, mas presente em todos os âmbitos da vida e da sociedade. O conceito de Bioregião oferece importantes insights neste sentido.

As Bioregiões são áreas que compartilham de uma combinação de fenômenos únicos e simultâneos: espaços geográficos com condições ecológicas similares em toda a sua extensão; grupos de pessoas que compartilham de uma história similar e uma mesma identidade, e que ocupam o mesmo espaço geográfico (BRUNCKHORST, 2017). Desenvolvido na Itália no ano de 2004, o conceito de Bioregião ressalta a condição de similaridade entre fatores ambientais e sociais para o desenvolvimento de estratégias de planejamento territorial integrado - o intuito é reduzir as disparidades regionais e as divergências no diálogo entre atores e perspectivas entre grupos, facilitando a construção de um território participativo e autônomo, onde predominam parâmetros ecológicos e culturais coesos e diretrizes a serem seguidas por todos os participantes e setores envolvidos (WAISSBLUTH, 2016). Tais parâmetros são criados em comum envolvimento comunitário a partir de ações conjuntas e coordenadas entre todos.

A Bioregião trabalha com múltiplas escalas territoriais com o intuito de assegurar coerência e alinhamento entre as ações tomadas em diferentes contextos. A variação de escala de planejamento territorial permite a visualização dos diferentes fenômenos de uma região. Escalas menores oferecem um bom entendimento do contexto geral e influências macro. O planejamento nestas escalas geralmente se expressa através de diretrizes e planos gerais. Escalas maiores, focadas no local, expressam um maior nível de detalhes do contexto existente. Cada escala pressupõe o envolvimento de atores específicos, com maior participação de órgãos públicos nas escalas regionais, e uma maior participação do setor privado, da sociedade civil e do cidadão nas escalas locais. A clara comunicação e alinhamento entre as escalas confere coerência ao planejamento territorial, e garante que decisões tomadas no plano local não sejam rendidas inválidas por desacordo com políticas regionais ou federais (HAAR, 1957).

A importância na variação da escala é também defendida pela teoria da hierarquia, que afirma que a natureza se organiza a partir da integração de diferentes subsistemas (por exemplo, comunidades), localizados em diferentes níveis ou escalas espaciais (por exemplo, locais ou regionais) (WANG, 2019). A teoria afirma que sistemas biológicos pequenos tendem a sofrer mudanças mais rapidamente que sistemas grandes, uma vez que a escala dos processos naturais é diretamente proporcional à sua estabilidade (NORTON, 1992). A estabilidade, nesse caso, tem uma forte relação com a qualidade de sincronicidade, ou seja, a capacidade de gerar movimentos coordenados simultâneos em diferentes localidades (LIEBHOLD, 2004). Sugerimos que o que promove a sincronicidade é o grau de conectividade entre elementos e entre sistemas, permitindo que trocas de informações aconteçam de forma eficiente na rede, assim permitindo respostas rápidas. Nesse sentido, quanto maior o ecossistema natural preservado e a qualidade de conectividade nele existente, maior será sua estabilidade e a saúde de seus processos naturais.

Do ponto de vista social, a sincronicidade é alcançada a partir de algumas condições. De forma simplificada, comunidades que compartilham de uma mesma história e conectam-se ao mesmo espaço, geralmente compartilham de valores e visões de mundo similares, e que informam suas ações. Não entraremos aqui no mérito das diferenças entre classes sociais e diferenças nas percepções de realidade. A similaridade, nesse caso, favorece a estabilidade (WANG, 2019), contribui para a construção do consenso, uma maior objetividade de planejamento e favorece a possibilidade de uma ação coordenada.

A proposição de um planejamento integrado e coordenado entre diferentes escalas nasce de algumas constatações importantes. A primeira é a de que os órgãos governamentais não performam de forma otimizada quando são responsáveis pela tarefa de gestão, implementação e monitoramento em todas as escalas do território. 
O papel centralizado do Estado sobrecarrega sua estrutura e atenua a responsabilidade e participação do cidadão comum na construção do bem estar coletivo. Através de uma ação colaborativa entre diferentes atores, um senso de comunidade renovado, aliado a uma maior gestão democracia local (GALLENT, 2019) e real pode ser construído, fortalecendo o sentimento de pertencimento e valorização do local. Alguns exemplos de gestão participativa são encontrados nos CPR - Common Property Resources ou Recursos de Propriedade Comum, territórios ou recursos naturais comunitários. Diferentemente dos comuns públicos que são open source, os CPR são de propriedade de um grupo restrito de pessoas, que deliberadamente concordam em coletivamente assumir a tarefa de investir e manejar recursos naturais, visando uma melhor gestão de risco e uma maior garantia de sucesso nas empreitadas assumidas (DASGUPTA, 2005).

Para que o planejamento de Bioregiões seja uma realidade, os desafios presentes no processo de construção devem ser devidamente identificados e realisticamente abordados. O planejamento territorial integrado implica a criação de mecanismos específicos de mapeamento, decisão, ação e monitoramento dos desafios rurais locais. Estes instrumentos deverão ser adaptáveis a diferentes tamanhos de grupo, espaços e culturas, permitindo interações relevantes a cada cenário.

Nesse sentido, sugere-se aqui que diferentes mecanismos de permeabilidade sejam imaginados, permitindo que a comunidade se beneficie da gestão compartiIhada do território em comum, e não unicamente da gestão de suas propriedades dentro deste território. Isso implica na flexibilização do conceito de propriedade individual em prol de uma unidade territorial mais ampla e coesa - uma espécie de cooperativa de proprietários bioregionais. Inúmeros desafios legais e sociais surgirão ao longo do processo, a serem observados, debatidos e compartilhados para que a proposta de Bioregião se torne uma solução possível.

\section{Conclusão}

Para que haja uma nova narrativa para o planeta, a sociedade global deve promover a reavaliação dos modelos de planejamento territorial e desenvolvimento adotados, refletindo sobre a validade dos valores e visões de mundo sustentados até o momento, e a relevância da herança histórica de nossas instituições ao contexto atual em que vivemos.
Com o vasto desenvolvimento da ciência e o aprofundamento do conhecimento acerca as relações de interconexão entre sociedade humana e o ambiente natural, entendemos hoje os ecossistemas naturais como sistemas primários que sustentam a vida. Todas as atividades que desempenhamos - agrícolas, industriais, sociais, de serviços - são, na verdade, sistemas secundários que dependem da conservação dos sistemas primários. Assim, o ser humano começa a visualizar diante de si as possibilidades para a construção de uma vida integrada com o território e com outros seres vivos. A partir desta perspectiva renovada, muitas são as oportunidades a serem construídas coletivamente na direção de territórios e modelos de vida saudáveis.

\section{Referências}

FRIEDMANN, John. Planning in the Public Domain: From Knowledge to Action. Princeton University Press. 1987.

CABEZA, Angel Massiris. Fundamentos Conceptuales y Metodologicos del Ordenamiento Territorial. Unievrsidad Pedagocica y Tecnológica del Colombia Tunja. 2005.

LYNCH, Kevin. Site Planning. The MIT Press. Cambridge, Massachusetts. 1984.

HAARS, Charles M. Regionalism and Realism in Land Use Planning. University of Pensilvania Law Review. 1957.

NORTON, Bryan G. et al. Scale and Biodiversity Policy: A Hierarchical Approach. AMBIO A Journal of the Human Environment. 1996.

SANTOS, Milton. A Natureza do Espaço. Técnica e Tempo. Editora da USP. São Paulo. 2003.

MARICATO, Ermínia. Urbanismo na periferia do mundo globalizado. Metrópoles brasileiras. São Paulo em Perspectiva. 2000.

DASGUPTA, Parta. Common Property Resources: Economic Analysis. 2005.

LIEBHOLD, Andrew M. Spatial Synchrony in Populations Dynamics. Annual Review of Ecology Evolution and Systematics. 2004.

WANG, Shaopeng et al. Stability and synchrony across ecological hierarchies in heterogeneous metacommunities: linking theory to data. Ecography. 2019. 
WIGGINS, Steve. How special are rural areas? The economic implications of rural development. Development Policy Review. 2001.

GALLENT, Nick et al. Defining rurality and the scope of rural planning. Routledge.2019.

ABRAMOVAY, Ricardo. Muito Além da Economia Verde. Editora Abril. São Paulo. 2012.

ABRAMOVAY, Ricardo. O Brasil se distancia cada vez mais da infraestrutura sustentável. Disponível em: https://ricardoabramovay.com/2021/06/o-brasil-se-distancia-cada-vez-mais-da-infraestrutura-sustentavel/. Acesso em: 4 agosto, 2021.

MAXWELL, Nicholas. Karl Popper, Science and Enlightment. UCL Press. London. 2017.

BRUNCKHORST, David. Building capital through bioregional planning and biosphere reserves. Ethics in Science and Environmental Politics. 2001.

DALLABRIDA, Valdir R. Territory Planning And Management: The Theory Debate In Brazil And A Prospect Of Practice According To Theoretical Contributions On Territorial Governance. Revista Brasileira de Gestão e Desenvolvimento Regional. Taubaté.2015.

ZANON, Elisa Roberta. Planejamento Territorial: Reflexões sobre uma cultura em construção no Brasil. ENANPUR, Natal. 2019.

Bioregiões, Uma Estratégia integrada de desenvolvimento de territórios rurais. Website: Inovações Para a Agricultura. Disponível em: www.inovacao.rederural.pt. Acesso em: 14 agosto, 2021.

THE WORLD BANK Data. Urban land área (Sq. Km). Disponível em: https://data.worldbank.org/indica-

tor/AG.LND.TOTL.UR.K2?end=2010\&start=1990\&view=chart. Acesso em 5 agosto, 2021.

FAO. Land uso in agriculture by the numbers. 2020. Disponível em: http:/www.fao.org/sustainability/news/detail/en/c/1274219/. Acesso em 10 agosto, 2021.
WAISSBLUTH, Dominique. Bioregionalism, community and environmental ethics: an approach to geofraphical borderlines. Intus-Legere Filosofia. 2016.

IBGE. Classificação e Caracterização dos Territórios Rurais e Urbanos no Brasil. Uma Primeira Aproximação. Estudos e Pesquisas - Informação geográfica, n. 11. Rio de Janeiro. 2017. 